\title{
Effects of Multiple Sprint Test on Average Speed and Exercise Heart Rate in Amateur Soccer Players
}

\author{
Cuma Ece ${ }^{1}$, Murat Şen ${ }^{1}$, Semra Çetin ${ }^{1}$, Alaeddin Aydoğan ${ }^{2}$, H. Nedim Çetin ${ }^{1}$ \\ ${ }^{1}$ Faculty of Sport Sciences, Sakarya University, Sakarya, Turkey \\ ${ }^{2}$ Faculty of Sport Sciences, Lokman Hekim University, Ankara, Turkey \\ Correspondence: H. Nedim Çetin, Faculty of Sport Sciences, Sakarya University, Sakarya, Turkey.
}

Received: April 8, 2019

doi:10.11114/jets.v7i6.4197
Online Published: April 24, 2019

URL: https://doi.org/10.11114/jets.v7i6.4197

\begin{abstract}
The purpose of this study is to investigate the effects of multiple sprints on average speed and exercise heart rate of U18 female and U18 male amateur soccer players. In this study, totally 42 amateur soccer players including U18 $(n=21)$ and U18 $(n=21)$ players performed 7 repetitive sprints of 34.2 meters with a 25 seconds jog of 50 meters distance. During exercise and recovery period, heart rate per minute was recorded by Polar Heart Rate Telemetry. In statistical analyzes, t-tests were used in two groups comparisons, while the effects of other variables on average speed and cardiovascular parameters were determined by two way analyzes of variance.

Results of this study, U18 male players' average speed of $5.14 \mathrm{~m} / \mathrm{sec}$ is higher than the U18 female players' average speed of $4.62 \mathrm{~m} / \mathrm{sec}$. The physical characteristics of U18 male and U18 female amateur soccer players were different in favors of the U18 male players, and that gender was significantly effective on the average speed rather than the number of sprints. Heart rate per minute has continually increased in different characteristics at the start, finish and recovery periods of the sprints until the finish of the seventh sprint in both amateur U18 male and U18 female. It found increase in the Sprint time were as follows; U18 female $0.40 \mathrm{sec}$ and U18 male 0.20 second. Decrease in the average speed was U18 female 0.28 sec., and U18 male 0.15 second.

Conclusion, in multiple speed tests, maximum and average speed of the U18 amateur female and male soccer players, the decrease rate in their speed and their cardiovascular responses show differences. In U18 Amateur, males seem to be faster and have the ability of keeping speed at a high level, and the ability of intensity and recovery in maximal level in a short time than the females. In the Bangsbo test, the recovery time in men should be less than 25 seconds.
\end{abstract}

Keywords: soccer, average speed and cardiovascular response

\section{Introduction}

Soccer is an intermittent sport which requires players to undertake many technical, physical, and tactical actions. Previous research suggests that agility, power development, repeated sprint ability and endurance capability represent determinant factors for success in soccer (Chtara et al., 2017). Even perception of colors affects success (İmamoğlu, 2010; İmamoğlu, 2011). Soccer is described as a multiple-sprint sport, reflecting the need for players to repeatedly sprint throughout the duration of a match. It is thought that sprint efforts are associated with crucial moments of match play, and, as a result, the ability to repeatedly sprint represents an important performance characteristic. To measure this performance characteristic, tests of repeated-sprint ability have become popular. In the literature repeated-sprint ability has been defined as the ability to perform repeated short-duration sprints over a brief period of time, with tests of repeated-sprint ability reflecting an intense period of play during a match. Tests of repeated-sprint ability have been shown to distinguish between both adult and youth players of varying standards; however, the link with performance in a match is less clear (Reilly, 1997; Spencer et al.,, 2004; Abrantes et al., 2004). Abrantes et al., (2004) examined to football players' sprint test performance across different ages and levels of competition and reported that the main effect of sprint trial was also statistically significant. According to statistical analysis, mean sprint times from the first trial were significantly slower than mean sprint times from the second, third and fourth trial. Results from the fifth, sixth and seventh trials were slower. Soccer is a complex sport requiring the repetition of many diverse activities (e.g., jogging, sprinting and jumping) over 90 min (Bangsbo et al., 1991; Mohr et al., 2003; Wither et al., 1982). Soccer players are required to repeatedly produce maximal or near maximal sprints of short duration $(1-7 \mathrm{~s})$ with brief recovery periods 
(Bangsbo et al, 1991; Wither et al., 1982, 43). Therefore, the ability to repeat multiple sprints at high speed (i.e., RSA) is important for soccer physical performance (Bangsbo, 1997; Wragg et al., 2000).

In today's soccer, becoming a matter of primary importance of physical aspects and increasing of social popularity from day to day caused of a necessity. This necessity is that improving physical aspects of soccer players and maintaining these aspects at maximum level (Luxbacher, 1986). In general, during a 90-min soccer match, $80 \%-90 \%$ constitutes to moderate to low intensity whilst the remaining 10\%-20\% is high intensity running (Bloomfield et al., 2007; Rienzi et al., 2000; İmamoğlu and Kılcıgil, 2007). Several authors have observed players at the top of their national league (Bangsbo et al., 1991; Bangsbo, 1994). These studies have suggested that the amount of high-intensity exercise is a valid measure of physical performance in soccer. One of the most important parts of today's soccer players' performance is that they are able to succeed at high speed short-distance runs of straight or different directions as much as possible from the beginning to the end of the game. The ability of gaining speed in short distance and time is important while possessing ball from the opponents or while stopping them from maintaining the ball (Ekblom, 1994). It is stated that, during a soccer game, many of the sprints done with maximum power are generally straight and the sprint distances change between 5-50 meters (Yamak and İmamoğlu, 219). On the other hand, Withers et al., (1982) state that during a game, maximal sprint distance changes between 20 and 30 meters, players do approximately 100 speed sprints, they reach maximal speed after 30 meters, they keep their speed between the 30 and 60 meters of the sprint and their speed decreases after that. Ekblom (1994) claims that during a soccer game average sprint distance is 15 meters and maximum sprint distance is 40 meters. The same researcher states that acceleration in sprints with high starts from a stable position up to 30 meters and also maximal running speed in sprints between 30 and 50 meters which start with gaining speed can be measured.

Based on Nikolaidis et al., (2016) findings, it is evident that coaches should increase their focus on the development of the sprint ability in football players. When the running distance is divided by the running time, average running speed can be measured in $\mathrm{m} / \mathrm{sec}$ (Ekbolm, 1994). Sprinting has been suggested as the most frequent action performed before a goal Haugen et al., 2014). Players in the German national football team were found to perform $~ 17$ sprints per game (Schimpchen et al., 2015). It has been reported that although sprinting and high intensity actions represent only 10 to $15 \%$ of covered running distance, they are extremely decisive for the outcome of the game in both elite male and female soccer (Gabbett and Mulvey, 2008).

Therefore, the aim of this study is to determine the effects of repetitive sprints on average speed and exercise heart rate of male and female young amateur soccer players.

\section{Methods}

\subsection{The Study Group and Design}

In the Sakarya Gymnasium in January 2015, 42 amateur soccer players, 21 of whom were male (U18) and 21 of whom were female (U18), participated in this study voluntarily as subjects. Body weights were measured with an accurate weighing machine $(0.1 \mathrm{~kg})$ and heights were measured with the help of a metal bar on this weighing machine $(0.1 \mathrm{~mm}$ accurate). All of the speed measurements were done in the afternoon with Prosport TMR ESC 2100 model multi-doored telemetric chronometers. From high start stable position the subjects were made to run 7 repetitive maximum effort sprints of 34,2 meters and also to take multiple speed tests with 25 seconds 50 meters run in-between the sprints (Bangsbo, 1994).

At the very beginning of the start, the footballer's front toe tips were placed on the beginning of the running distance and thus the subjects were made to get a high start. Average run speed was measured in $\mathrm{m} / \mathrm{sec}$ by dividing the running distance by the running time. The percentage of the difference between the mean of the first two runs and the mean of the last two runs was taken as the ratio of fatigue. Moreover, the best running time and the mean time of 7 runs were calculated. The number of heart beats in the course of exercise and recovery were determined by Polar Heart Rate Telemeter.

\subsection{Statistics}

Descriptive statistics about the Footballers' running times and average speed in different sprints were calculated. T-test was used in comparing the physical characteristics of the U18 amateur male and female soccer players. Two-way variance analyses were used to determine the effects of 7 different speed runs and gender on the Footballers' average speed and the number of heart beats during exercises the effects of the different phases of recovery and gender on the number of heart beats per minute, systolic and diastolic blood pressure. 


\section{Results}

Table 1. Comparison of the male and female players' physical characteristics

\begin{tabular}{|c|c|c|c|c|c|}
\hline Variants & Group & $\mathbf{N}$ & $\mathrm{X} \pm$ SD. & Min-Max & t-value \\
\hline \multirow{2}{*}{$\begin{array}{l}\text { Height } \\
(\mathrm{cm})\end{array}$} & U18 Female & 21 & $162.11 \pm 4.95$ & $150.9-169.0$ & \multirow{2}{*}{$-8.12 * *$} \\
\hline & U18 Male & 21 & $175.23 \pm 4.74$ & $166.5-183.0$ & \\
\hline \multirow{2}{*}{$\begin{array}{l}\text { Weight } \\
\text { (kg) }\end{array}$} & U18 Female & 21 & $60.21 \pm 7.16$ & $44.4-69.6$ & \multirow{2}{*}{$-6.51 * *$} \\
\hline & U18 Male & 21 & $72.35 \pm 7.52$ & $59.2-87.0$ & \\
\hline \multirow{2}{*}{$\begin{array}{l}\text { Age } \\
\text { (years) }\end{array}$} & U18 Female & 21 & $17.30 \pm 3.92$ & $15.0-18.0$ & \multirow{2}{*}{1.02} \\
\hline & U18 Male & 21 & $17.37 \pm 2.06$ & $15.0-18.0$ & \\
\hline
\end{tabular}

$* * \mathrm{p}<0,01$

Table 2. Running time and average speed values of the male and the female players

\begin{tabular}{|c|c|c|c|c|c|c|c|c|}
\hline \multirow{3}{*}{$\begin{array}{l}\text { Sprint } \\
\text { Number }\end{array}$} & \multicolumn{4}{|c|}{ 34.2 meters Running Time (sec) } & \multicolumn{4}{|c|}{ Average Running Speed(meters/sec) } \\
\hline & \multicolumn{2}{|l|}{ U18Male } & \multicolumn{2}{|l|}{ U18 Female } & \multicolumn{2}{|l|}{ U18 Male } & \multicolumn{2}{|l|}{ U18 Female } \\
\hline & $\mathbf{X} \pm$ SD. & Min-Max & $\mathrm{X} \pm \mathrm{SD}$ & Min-Max & $\mathrm{X} \pm \mathrm{SD}$ & Min-Max & $\mathrm{X} \pm \mathrm{SD}$ & Min-Max \\
\hline 1 & $6.57 \pm 0.58$ & $5.21-7.28$ & $7.18 \pm 0.72 *$ & $5.59-8.09$ & $5.21 \pm 0.53$ & $4.72-6.59$ & $4.76 \pm 0.52 *$ & 4.24-6.16 \\
\hline 2 & $6.51 \pm 0.71 *$ & $4.98-7.69$ & $7.25 \pm 0.59$ & $5.92-8.07$ & $5.25 \pm 0.65 *$ & $4.47-6.91$ & $4.77 \pm 0.40$ & $4.26-5.89$ \\
\hline 3 & $6.65 \pm 0.69$ & $4.98-7.43$ & $7.41 \pm 0.48$ & $6.28-8.05$ & $5.14 \pm 0.68$ & $4.60-6.90$ & $4.79 \pm 0.31$ & $4.25-5.53$ \\
\hline 4 & $6.67 \pm 0.70$ & $5.03-7.53$ & $7.47 \pm 0.57$ & $6.38-8.39$ & $5.13 \pm 0.67$ & $4.58-6.81$ & $4.58 \pm 0.33$ & $4.11-5.28$ \\
\hline 5 & $6.68 \pm 0.73$ & $4.96-7.87$ & $7.58 \pm 0.53$ & $6.34-8.39$ & $5.12 \pm 0.69$ & $4.36-6.93$ & $4.51 \pm 0.31$ & $4.09-5.31$ \\
\hline 6 & $6.70 \pm 0.72$ & $5.17-7.85$ & $7.60 \pm 0.58$ & $6.68-8.39$ & $5.10 \pm 0.66$ & $4.37-6.63$ & $4.50 \pm 0.29$ & $4.08-4.97$ \\
\hline 7 & $6.77 \pm 0.63$ & $5.09-7.51$ & $7.63 \pm 0.49$ & $7.03-8.18$ & $5.05 \pm 0.55$ & $4.56-6.77$ & $4.48 \pm 0.23$ & 4.18-4.89 \\
\hline Total & $6.65 \pm 0.68$ & 4.96-7.87 & $7.41 \pm 0.54$ & 5.59-8.39 & $5.14 \pm 0.62$ & $4.36-6.93$ & $4.62 \pm 0.37$ & 4.08-6.16 \\
\hline
\end{tabular}

*Best running time or average speed.

Table 3. The effects of gender and sprint number on running time and average speed

\begin{tabular}{llcccc}
\hline Dependent Variable & Factors & Total Square & df & Average Square & \multicolumn{1}{c}{ F } \\
\hline \multirow{2}{*}{$\begin{array}{l}\text { Running Time } \\
\text { (sec) }\end{array}$} & United & 47.28 & 7 & 6.74 & $16.35^{* *}$ \\
\cline { 2 - 6 } & Gender & 44.30 & 1 & 44.19 & $112.24 * *$ \\
\cline { 2 - 6 } $\begin{array}{l}\text { Average Speed } \\
(\mathbf{m} / \text { sec) }\end{array}$ & Sprint Number & 3.09 & 6 & 0.51 & 1.22 \\
\hline & United & 26.45 & 7 & 2.05 & $7.03^{* *}$ \\
\cline { 2 - 6 } & Gender & 24.23 & 1 & 24.20 & $99.46^{* *}$ \\
\cline { 2 - 6 } & Sprint Number & 1.60 & 6 & 0.23 & 1.01 \\
\hline
\end{tabular}

$* * \mathrm{p}<0.01$

Table 4. The Descriptive Statistics of the Male and the Female Players' Heart Beat Rates in the Start, Finish of the Sprints and in the Last Quarter of the Recovery Run

\begin{tabular}{|c|c|c|c|c|c|}
\hline Variables & Group & Mean & S. Deviation & Min. & Max. \\
\hline \multirow{2}{*}{ Start } & U18 Male & 176.62 & 21.50 & 89.00 & 197.00 \\
\hline & U18 Female & 167.46 & 21.16 & 93.00 & 192.00 \\
\hline \multirow{2}{*}{ Finish } & U18 Male & 183.28 & 19.15 & 105.00 & 201.00 \\
\hline & U18 Female & 175.89 & 19.42 & 109.00 & 211.00 \\
\hline Last & U18 Male & 185.91 & 8.95 & 143.00 & 198.00 \\
\hline $\begin{array}{l}\text { Quarter of the } \\
\text { Recovery }\end{array}$ & U18 Female & 178.62 & 12.35 & 152.00 & 194.00 \\
\hline
\end{tabular}

Table 5. The effects of gender and sprint number on the number of heart beats in the different phases of the speed runs

\begin{tabular}{|c|c|c|c|c|c|}
\hline Dependent Variable & Factors & Total Square & df & Average Square & $\mathbf{F}$ \\
\hline \multirow{3}{*}{ Start } & United & 102140.290 & 7 & 14461.90 & $77.53 * *$ \\
\hline & Gender & 6120.945 & 1 & 6101.95 & $32.48 * *$ \\
\hline & Sprint Number & 95239.345 & 6 & 15846.56 & $85.37 * *$ \\
\hline \multirow{3}{*}{ Finish } & United & 49266.676 & 7 & 7035.24 & $47.66 * *$ \\
\hline & Gender & 7892.861 & 1 & 7882.86 & $52.54 * *$ \\
\hline & Sprint Number & 41493.815 & 6 & 6878.97 & $45.44 * *$ \\
\hline \multirow{3}{*}{$\begin{array}{l}\text { The Last Quarter of the } \\
\text { Recovery }\end{array}$} & United & 14521.668 & 7 & 2055.95 & $28.98 * *$ \\
\hline & Gender & 6325.147 & 1 & 6315.15 & $72.16^{* *}$ \\
\hline & Sprint Number & 8027.521 & 6 & 1346.10 & $18.36^{* *}$ \\
\hline
\end{tabular}

$* * \mathrm{p}<0.01$ 
Table 7. The Effects of the first and last two sprints means and Gender on the Male and the Female Players' Sprint Time and Average Speed

\begin{tabular}{|c|c|c|c|c|c|}
\hline $\begin{array}{l}\text { Dependent } \\
\text { Variable }\end{array}$ & Factors & Total Square & df & Mean Square & $\mathbf{F}$ \\
\hline \multirow{3}{*}{$\begin{array}{l}\text { Sprint Time } \\
\text { (sec) }\end{array}$} & United & 6656.97 & 1 & 6624.93 & $17982.1 * *$ \\
\hline & $\begin{array}{l}\text { The first and last } \\
\text { two sprints Means }\end{array}$ & 2.329 & 1 & 2.32 & $7.2^{*}$ \\
\hline & Gender & 22.370 & 1 & 22.35 & $62.4 * *$ \\
\hline \multirow{3}{*}{$\begin{array}{l}\text { Average Speed } \\
(\mathbf{m} / \mathbf{s e c})\end{array}$} & United & 3347.49 & 1 & 3326.52 & $13983.1^{* *}$ \\
\hline & $\begin{array}{l}\text { The first and last } \\
\text { two sprints Means }\end{array}$ & 1.25 & 1 & 1.14 & $5.1^{*}$ \\
\hline & Gender & 12.24 & 1 & 12.13 & $52.7 * *$ \\
\hline
\end{tabular}

$* * \mathrm{p}<0.01$

Table 8. Relating the Heart Beat Rates of the Male and the Female Players at Different Times during the Recovery Phase

\begin{tabular}{|c|c|c|c|c|c|c|}
\hline \multirow{2}{*}{ Variables } & & \multirow{2}{*}{ Recovery Period } & \multicolumn{2}{|c|}{ U18 Male } & \multicolumn{2}{|c|}{ U18 Female } \\
\hline & & & $\mathrm{X} \pm \mathrm{SD}$ & Min-Max & $\mathrm{X} \pm \mathrm{SD}$ & Min-Max \\
\hline \multirow{3}{*}{$\begin{array}{l}\text { Heart } \\
\text { Rate } \\
\text { (beat/min) }\end{array}$} & Beat & $1^{\text {st }}$ Minute & $110.92 \pm 11.92$ & $89.0-128.0$ & $153.18 \pm 14.80$ & $121.0-172.0$ \\
\hline & & $3^{\text {rd }}$ Minute & $104.00 \pm 10.24$ & $79.0-124.0$ & $113.15 \pm 12.91$ & $86.0-142.0$ \\
\hline & & $5^{\text {th }}$ Minute & $100.11 \pm 10.97$ & $72.0-122.0$ & $106.33 \pm 16.15$ & $74.0-136.0$ \\
\hline
\end{tabular}

Table 9. The Effects of Gender and Resting Period on the Heart Beat Rate during Recovery Phase

\begin{tabular}{llcccc}
\hline Dependent Variable & Factors & Total Square & df & Mean Square & F \\
\hline \multirow{2}{*}{$\begin{array}{l}\text { Heart Beat Rate } \\
\text { (beat/min) }\end{array}$} & United & 26880.62 & 3 & 8937.20 & $51.56^{* *}$ \\
\cline { 2 - 6 } & Gender & 12159.65 & 1 & 12158.65 & $67.30^{* *}$ \\
\cline { 2 - 6 } & Resting Period & 14821.96 & 2 & 7361.48 & $40.69^{* *}$ \\
\hline
\end{tabular}

$* * \mathrm{p}<0.01$

\section{Discussion}

In this study, Amateur U18 male soccer players' average age level was 17.30 years $(\mathrm{n}=21)$, average height level was $175.23 \mathrm{~cm}$, average weight was $72.35 \mathrm{~kg}$ and amateur U18 female soccer players' average age level was 17.37 years $(\mathrm{n}=21)$, average height level was $162.11 \mathrm{~cm}$, average weight was $60.21 \mathrm{~kg}$ (Table 1). Between U18 male and U18 female soccer 0.01 level was differences height and weight meaningful. Between of Age was no differences ( $>0.05)$.

Bangsbo's (1994) 7.10 seconds average running time with the range of 6.83-7.31 seconds for 11 top-level Denmark soccer players is higher than the 6.58 seconds value for the males and lower than the 7.45 seconds average of the females in our study. Imamoglu et al., (2012) in study, the sprint averages were between $5.98 \mathrm{sec}-7.78 \mathrm{sec}$. It has also been observed that players at a higher standard of competition perform significantly more high-intensity running than those at a lower standard (Bangsbo et al., 1991). Özdemir et al., (2014) study, results indicated that in repeated sprint ability, best sprint time and total sprint time improved with age while no improvement was obtained in performance decrement. Imamoğlu et al., (2013) in one study, while no significant difference was observed between professional and amateur soccer players in terms of their speed performance. In this study, as for the average running time connected with the sprint number, neither U18 males nor U18 females have a tendency for continuous increase. While the U18 male players' average running time in the first, 3th, 5th and 7th sprints are respectively $6.57,6.65,6.58$ and 6.77 seconds; the same values are 7.18,7.41, 7.58 and 7.63 seconds for the U18 female players. Similarly, while the average speed values of the first, 3th, 5th and 7th sprints are respectively $5.21,5.25,5.12$ and $5.05 \mathrm{~m} / \mathrm{sec}$ for the U18 males, they are respectively 4.76 , $4.79,4.51$ and $4.48 \mathrm{~m} / \mathrm{sec}$ for the U18 female. In total, the U18 male players' average speed of $5.14 \mathrm{~m} / \mathrm{sec}$ is higher than the U18 female players' average speed of $4.62 \mathrm{~m} / \mathrm{sec}$. For the U18 male, average speed range between $4.36-6.93 \mathrm{~m} / \mathrm{sec}$, and between $4.09-6.16 \mathrm{~m} / \mathrm{sec}$ for the U18 female (Table 2). These results show that U18 amateur footballers of our study are faster than the U18 amateur females. In this study, the running time and accordingly average speed changed for the young amateur male and female players, no change was seen connected with the number of speed run (Table 3).

Yamak and İmamoğlu (2019)in a study, in between U16 and U 18 category soccer players, it is found out a meaningful difference on the average speed in the first two sprints and the average speed in the last 2 sprints $(p<0,001)$. İmamoğlu et al., (2018) in a study, run time, the average of 1st and 2nd sprint (the best run average) is 3,61 second, the average of 9th and 10th sprint (the best last average) is 4,24 sn. There were a statistically meaningful difference between the two average 
$(\mathrm{p}<.01)$. In this study, Male soccer players are the best 2 nd runner and female soccer players are the best 1 st runner. The running speed has generally decreased gradually $(5,6$, and 7 th sprint). This difference between females and males can be explained with a partial renewal of phosphate deposits in males, and poor renewal in females during 25 seconds 50 meters jogs, and with a decrease in the force of pushing the ground because the females have less muscle mass when compared to the males and also different anthropometric structure.

İmamoğlu et al., (2012) in study, found the end of the sprints heart beat frequencies were found as Erzurum sports 172.57 beats/min, Samsun Power 185.95 beats/min, 1st amateur 181,93 beats/min, 2nd amateur 178.81 beats/min and students 183.72 beats/minute. After the 5 minute relaxation following the sprints the heartbeat frequencies decreased by 98,30 beats/min for Erzurumspor, 113.34 beats/min for Samsun power, 97.56 beats/min for 1st amateur, 101.01 beats/min for 2nd amateur and 122.89 beats/min for the students. Mc Ardle et al. (1967) in their study on male subjects found that the maximum number of heart beats for 60 yards (55 meters) and 200 meters were respectively 177 and 191 beat/min for the contender athletes, the same values were reported as 162 and $168 \mathrm{beat} / \mathrm{min}$ for the subjects with no training beforehand. On the other hand, the average maximal number of heart beats were reported as 179 beats/ min for the South Australian soccer players (Withers et al., 1982), 176 beats/ min for the West Germany National Team soccer players (Nowacki et al., 1988) and 198 beat/ min for the English League soccer players (Reilly, 1997). All of these values are similar to the norms of normal population (Ekblom, 1994). I this study, in the start and finish of the sprint and in the last quarter of the recovery average heart beat rates are respectively $176.62,183.28$ and 185.91 beat $/ \mathrm{min}$ for the males, the same values are respectively $167.46,175.89$ and 178.62 beats/min for the females (table 4). During the start, finish and last quarter of the recovery sprint which are accepted as the different parts of speed runs, between amateur U18 males and U18 amateur females the number of heart beats per minute changes significantly $(\mathrm{p}<0.01)$ in-between the sprints. These values show that the cardiovascular intensity increases to the maximal level with a great speed in the multiple sprint test (table 5). The average values of U18 Males soccer in this study are similar to those of the in other studies and the average values of the subjects with no training beforehand are similar to those of the female players in our study. Cardiovascular responses are worse in female soccer players than male soccer players.

Fatigue or impaired performance in soccer occurs during various phases in a game, and different physiological mechanisms appear to operate in different periods of a game (Mohr et al., 2005). In Bangsbo's study, the 0.64 seconds mean fatigue index with the range of 0.15-0.92 seconds for the 11 top-level Denmark soccer players seems to be higher than the means of 0.10 and 0.17 seconds reported respectively for the male and the female in our study. Imamoğlu et al, (2012) in study, found that fatigue rates were between 0.27- 0.72 seconds. In this study, found increase in the Sprint time were as follows; U18 female $0.40 \mathrm{sec}$ and U18 male 0.20 second. Decrease in the average speed was U18 female 0.28 sec., and U18 male 0.15 second (Table 6).

Five minutes after exertion, if the athlete's heart beats number is under 115 in a minute, his performance is good; if it is under 105 per minute, his performance is very good; and if it is under 100 beats per minute, this shows the athlete's state of high performance trained (Zint and Eisenhut, 1994). In this study, the difference is that male footballer's heart rates fell less than that female footballers. The reason of this case may be related to the difference of condition and physical exertion in the tests. For the time for pulse to return to the normal after efforts depends on the workload during the exercise and the person's condition level. Good-conditioned people's pulse returns to the normal faster following the exercise. Balsom et al. (1992) observed that performance in a 30-m sprint could be maintained when subjects have a recovery period of $120 \mathrm{~s}$ between each sprint, but a marked decrease was found when the recovery time was $30 \mathrm{~s}$. This means that in order to evaluate an athlete's ability to recover from intense exercise the rest period between $30-\mathrm{m}$ sprints should be $30 \mathrm{~s}$ or shorter. In the light of these findings, by evaluating different sides of the speed performances of the U18 amateur male and the U18 amateur female footballers training content, intensity and capacity should be determined.

While the multiple sprint test used in this study developed by Bangsbo (1994) seems to be suitable for the females in the occurrence of fatigue as a result of the repetition of speed runs, it is not suitable for the U18 males as it causes early recovery and late fatigue. For the U18 males, shorter distance recovery runs should be preferred between the sprints.

In this study, the 110.92 beat /min number of heart beats in the first minute decreased to $100.11 \mathrm{beat} / \mathrm{min}$ at the fifth minute for the U18 males and the 153.18 beat/ min decreased to 106.33 for the females. At the very end of the multiple tests, during recovery, heart beat numbers per minute change significantly depending on the gender and relaxation time (table 9). These values show that the male players have a quicker recovery ability than the female players. Gender difference can be a result of the males' having max VO2's greater than the female in the rate of 5\%-30\%, and having lower body fat percentage than the female (McArdle et al., 1981). In this study, the difference is that U18 male footballer's heart rates fell less than that U 18 female footballers. The reason of this case may be related to the difference of condition and physical exertion in the tests. For the time for pulse to return to the normal after efforts depends on the workload during the exercise and the person's condition level. Good-conditioned people's pulse returns to the normal faster following the exercise. Various factors such as age, gender, body posture and person's condition level have an 
impact on the respond which circulatory system gives to the muscle exercise (Yamak and Imamoğlu, 2019). After exercising, recovery in men is very fast in the first one minute and it gets slower in the following minutes. The fast decreasing has lasted about the first 3 minutes and it decreases slowly between $3 \mathrm{rd}$ and 5 th minutes.

In conclusion, in multiple speed tests, maximum and average speed of the U18 amateur female and male soccer players, the decrease rate in their speed and their cardiovascular responses show differences. In U18 Amateur, males seem to be faster and have the ability of keeping speed at a high level, and the ability of intensity and recovery in maximal level in a short time than the females. Every category, in order to make an accurate determination of the quality and intensity of speed studies, photocell chronometers and wireless heart beat measurement devices should be used. In the Bangsbo test, the recovery time in men should be less than 25 seconds.

\section{References}

Abrantes, C., Maçãs, V., \& Sampaio, J. (2004). Variation in football players' sprint test performance across different ages and levels of competition. Journal of Sports Science \& Medicine, 3(1), 44.

Balsom, P. D., Seger, J. Y., Sjödin, B., \& Ekblom, B. (1992). Maximal-intensity intermittent exercise: effect of recovery duration. International Journal of Sports Medicine, 13(07), 528-533. https://doi.org/10.1055/s-2007-1021311

Bangsbo, J. (1994). Fitness training in football: a scientific approach. August Krogh Inst., University of Copenhagen.

Bangsbo, J., Nørregaard, L., \& Thorsoe, F. (1991). Activity profile of competition soccer. Canadian Journal of Sport Sciences, 16(2), 110-116.

Bloomfield, J., Polman, R., \& O'Donoghue, P. (2007). Physical demands of different positions in FA Premier League soccer. Journal of Sports Science \& Medicine, 6(1), 63.

Chtara, M., Rouissi, M., Haddad, M., Chtara, H., Chaalali, A., Owen, A., \& Chamari, K. (2017). Specific physical trainability in elite young soccer players: efficiency over 6 weeks' in-season training. Biology of Sport, 34(2), 137. https://doi.org/10.5114/biolsport.2017.64587

Ekblom, B. (Ed.). (1994). Football (soccer) (p. 227). Oxford: Blackwell Scientific Publications.

Gabbett, T. J., \& Mulvey, M. J. (2008). Time-motion analysis of small-sided training games and competition in elite women soccer players. The Journal of Strength \& Conditioning Research,22(2), 543-552. https://doi.org/10.1519/JSC.0b013e3181635597

Haugen, T. A., Tønnessen, E., Hisdal, J., \& Seiler, S. (2014). The role and development of sprinting speed in soccer. International journal of sports physiology and performance, 9(3), 432-441.

https://doi.org/10.1123/ijspp.2013-0121

İmamoğlu, G. (2010). The Effect of Colors on Sportive Performance, Mustafa Kemal University Physical Education and Sports Science, 1(2), 40-52.

İmamoğlu, G. (2011). The Effect of Colors on Sportive Performance in Football, Ataturk University Physical Education and Sports Science, 7(2), 1-5

İmamoğlu, O. R., İmamoğlu, O., Sarioğlu, I., \& Can, Y. F. (2012). The Comparison of Fatigue and Recovery Levels in Footballers of Different Categories through the Repetitive Sprint Test, 7-10 Februar, the 3rd International Conference on Sports and Exercise Science, Bangkok, Thailand.

İmamoğlu, O., \& Kılcıgil, E. (2007). Left-handedness issue at reaction time, vital capacity values and lateralization distribution of junior football players in Turkey. Spormetre the Journal of Physical Education and Sport Sciences, 5(3), 95-100.

İmamoğlu, O., Çebi, M., \& Yıldız, M. (2018). The research of consecutive sprint, jump and leg strength relationships in u15 football players. The Journal of International Social Research, 11(58), 913-918. https://doi.org/10.17719/jisr.2018.2604

Luxbacher, J. (1986). Soccer: Winning Techniques, Eddie Bowers Publishing Company, Iowa, pp.73.

McArdle, W. D., Foglia, G. F., \& Patti, A. V. (1981). Telemetered cardiac response to selected running events. Journal of Applied Physiology, 23(4), 566-570. https://doi.org/10.1152/jappl.1967.23.4.566

Mohr, M., Krustrup, P., \& Bangsbo, J. (2003). Match performance of high-standard soccer players with special reference to development of fatigue. Journal of Sports Sciences, 21(7), 519-528.

https://doi.org/10.1080/0264041031000071182

Mohr, M., Krustrup, P., \& Bangsbo, J. (2005). Fatigue in soccer: a brief review. Journal of sports sciences, 23(6), 593-599. https://doi.org/10.1080/02640410400021286 
Nikolaidis, P. T., Knechtle, B., Clemente, F., \& Torres-Luque, G. (2016). Reference values for the sprint performance in male football players aged from 9-35 years. Biomedical Human Kinetics, 8(1), 103-112. https://doi.org/10.1515/bhk-2016-0015

Nowacki, P. E., Cai, D. Y., Buhl, C., \& Krummelbein, U. (1988). Biological performance of German soccer players (professionals and juniors) tested by special ergometry and treadmill methods. Science and Football, 1, 145-157.

Özdemir, F. M., Yılmaz, A., \& İşler, A. K. (2014). Age related differences in repeated sprint performance in young football players. Hacettepe Journal of Sport Sciences, 25(1), 1-10.

Reilly, T. (1997). Energetics of high-intensity exercise (soccer) with particular reference to fatigue. Journal of Sports Sciences, 15(3), 257-263. https://doi.org/10.1080/026404197367263

Rienzi, E., Drust, B., Reilly, T., Carter, J. E. X. L., \& Martin, A. (2000). Investigation of anthropometric and work-rate profiles of elite South American international soccer players. Journal of Sports Medicine and Physical Fitness, 40(2), 162.

Schimpchen, J., Skorski, S., Nopp, S., \& Meyer, T. (2016). Are "classical" tests of repeated-sprint ability in football externally valid? A new approach to determine in-game sprinting behaviour in elite football players. Journal of Sports Sciences, 34(6), 519-526. https://doi.org/10.1080/02640414.2015.1112023

Spencer, M., Lawrence, S., Rechichi, C., Bishop, D., Dawson, B., \& Goodman, C. (2004). Time-motion analysis of elite field hockey, with special reference to repeated-sprint activity. Journal of Sports Sciences, 22(9), 843-850. https://doi.org/10.1080/02640410410001716715

Withers, R. T., Mercier, Z., Wasilewski, S., \& Kell, L. (1982). Match analyses of Australian professional soccer players. J Human Movement Studies, 8, 159-176.

Wragg, C. B., Maxwell, N. S., \& Doust, J. H. (2000). Evaluation of the reliability and validity of a soccer-specific field test of repeated sprint ability. European Journal of Applied Physiology, 83(1), 77-83. https://doi.org/10.1007/s004210000246

Yamak, B., \& İmamoğlu, O. (2019). Comparison of repetitive sprint performance for the u16 and u18 category soccer players. Universal Journal of Educational Research, 7(2), 394-399. https://doi.org/10.13189/ujer.2019.070212

Zintl, F., \& Eisenhut, A. A. (1994). Grundlagen, Methoden, Trainingssteuerung. BLV Sportwissen, München, 13.

\section{Copyrights}

Copyright for this article is retained by the author(s), with first publication rights granted to the journal.

This is an open-access article distributed under the terms and conditions of the Creative Commons Attribution license which permits unrestricted use, distribution, and reproduction in any medium, provided the original work is properly cited. 